\title{
Strength and stiffness predictions with focus on different acoustic measurement methods
}

\author{
A. Kovryga ${ }^{1}$ J. O. Chuquin Gamarra ${ }^{1}$ J. W. G. van de Kuilen ${ }^{1,2}$
}

Received: 24 September 2019 / Published online: 12 August 2020

(c) The Author(s) 2020

\begin{abstract}
Strength grading is an important step for the production of homogenous and high-quality solid wood material. In particular, for hardwoods, the use of non-visible characteristics is indispensable. Dynamic $\operatorname{MOE}\left(E_{d y n}\right)$ is an important parameter widely used for grading of softwoods and applicable to hardwoods as well. There are two common ways to measure $E_{d y n}$-ultrasound (US) wave propagation and longitudinal vibration (LV) method. Both methods are used in practice, however, due to the different inherent measurement techniques, the results differ. The current paper analyses the stiffness and strength coefficients of determination for several temperate European hardwood species and emphasizes the differences between the two measurement systems. The performance was analysed with regard to grading techniques, testing modes for the mechanical properties (tension and bending) and wood qualities. For more than 2861 pieces of European ash (Fraxinus excelsior), European beech (Fagus sylvatica), European oak (Quercus spp.) and maple (Acer spp.), the $E_{d y n}$ was measured using both techniques, and destructive tests (tension and edgewise bending) were applied. The results show that LV has higher coefficient of determination compared to the US $E_{d y n}$. The coefficient of determination for both methods and tensile application can be increased by calculating $E_{d y n}$ with average density. Furthermore, the results support species-independent strength grading of hardwoods. Further research on the effect of different wood qualities and sawing patterns is required.
\end{abstract}

\section{Introduction}

Temperate hardwoods are very well known for their excellent mechanical properties, which make them favourable for structural purposes. As a naturally grown material, wood shows high variation in mechanical properties. Strength grading is a crucial step for the production of homogenous and high-quality solid wood material with defined material properties. Whereas the research on softwoods has led to the high acceptance of the machine strength grading methods, the application of those methods to hardwoods is less frequent. The research activities in recent years in the field of strength grading and engineered wood products aimed to bridge knowledge gaps with regard to hardwoods.

Recent research activities have been focused on novel methods of non-destructive testing, as well as applying the

$\triangle$ A. Kovryga

kovryga@hfm.tum.de

1 Department of Wood Technology, Technical University of Munich, Winzererstrasse 45, 80797 Munich, Germany

2 Faculty of Civil Engineering and Geosciences, Delft University of Technology, Delft, The Netherlands established methods of machine strength grading to hardwoods. In focus of the mechanical strength grading, the dynamic MOE $\left(E_{d y n}\right)$ can be highlighted as a major criterion of interest. $E_{d y n}$ is a mechanical property of the material and describes the elastic behaviour of wood under dynamic cyclic stress and has been used to characterize wood material for decades (Kollmann and Côté 1968). The $E_{d y n}$ application for the strength grading of structural timber dates back to Görlacher (1990) and is currently one of the most frequent methods for the machine strength grading of wood. Generally, there are two possibilities to determine $E_{d y n}$, which are: ultrasound (US) wave propagation and longitudinal vibration (LV) method. Both methods are related to the acoustic properties of wood. In the first case, an ultrasound wave signal is generated and the propagation in wood is measured, whereas in the other case, a stress wave is induced using a hammer and the eigenfrequency of wood is determined. Nowadays, the eigenfrequency method has established itself as very robust and is the most frequently used method. The characteristic vibrations in the board can be detected contact-free using a laser vibrometer (Giudiceandrea 2005).

As a grading parameter, $E_{d y n}$ shows a high correlation to static MOE, for both softwoods (Bacher 2008) and 
hardwoods (Frühwald und Schickhofer 2005). Although for softwoods the correlation is higher, for hardwoods, the coefficient of determination of both US and LV measurement methods seems to be lower. The $R^{2}$ values reported for the strength prediction range from 0.18 to 0.36 for temperate hardwoods (Nocetti et al. 2016; Ravenshorst 2015) and are lower for the tensile strength prediction of temperate hardwoods shown for a variety of species $\left(R^{2}<0.25\right)$ (Ehrhart et al. 2016; Glos and Lederer 2000; Green and McDonald 1993). For tensile strength, the coefficient of determination depends on the quality of the material. Westermayr et al. (2018) report a high $R^{2}$ value of 0.48 for low-quality beech lamella, compared to the value achieved for high-quality ones with 0.22 (Ehrhart et al. 2016). The quality difference refers to visual grading criteria such as growth inhomogenities, visible slope of grain as well as knots. This might imply that for timber of rejectable quality, higher grading accuracy could be achieved. In most publications, the $E_{d y n}$ is determined using the LV. Therefore, questions arise regarding the performance of both methods and the differences between tensile and bending strength coefficient of determination. Frühwald and Hasenstab (2010) mention that the accuracy of the method is higher for LV.

The detection of the local inhomogeneities is crucial for hardwoods. LV and UV methods allow to determine the average wood quality. However, the local wood inhomogenities (such as knots and local slope of grain) are not detected using those methods. Both of them lead to a massive strength reduction (e.g., Kovryga et al. 2019). Therefore, the knot detection and measurement of the slope of grain using a variety of methods, such as laser scattering (Olsson et al. 2018), thermal conduction (Daval et al. 2015), automated image analysis (Ehrhart et al. 2018) and transversal ultrasound (Kovryga et al. 2020) are studied for the strength grading. However, due to their nature, those measurements have lower correlation to the elastic properties.
The present study aims to investigate the differences in the coefficient of determination between US and LV method on a large data pool of hardwood specimens tested at TU Munich in recent years. Both methods are compared regarding the correlation between $E_{d y n}$ and tensile strength and stiffness. Special focus is given to the differences between the species, the ability to apply species-independent strength grading, and the ability for bending and tensile strength prediction. The species ash, beech, maple and oak representing hardwood species with different anatomical structure (ringporous and diffuse porous) are investigated.

\section{Materials}

For the current study, in total 2681 specimens of European hardwoods-European ash (Fraxinus excelsior), European beech (Fagus sylvatica), oak (Quercus spp.) and maple (Acer spp.) were used. Table 1 gives an overview of the specimens and dimensions used. The length of the specimens varied between 3 and $5.5 \mathrm{~m}$. The specimens originated from different projects run at TU Munich over two decades. Beech and oak were tested by Glos and Lederer (2000) within the hardwood strength grading project. Ash and maple tested in bending originate from the project on the assignment of those species to the bending strength classes (D-Classes) by Glos and Torno (2008a, 2008b). Tension test data of ash and maple were obtained by Kovryga et al. (2019) within the project on hardwood strength grading. Details are described in the mentioned publications.

Table 2 summarizes the mechanical properties of the tested hardwoods. The tested specimens are representative of the tested wood species and, particularly, for the growth region in Central Europe. The mechanical property values are comparable to the values given in other publications. Thus, for ash, the mean tensile strength values

Table 1 Overview of specimens and dimensions

\begin{tabular}{|c|c|c|c|c|c|c|}
\hline \multirow[t]{2}{*}{ Species } & \multicolumn{3}{|l|}{ Bending } & \multicolumn{3}{|l|}{ Tension } \\
\hline & Cross-section $(b \times h)$ & $N$ & References & Cross-section $(b \times h)$ & $N$ & References \\
\hline $\begin{array}{l}\text { European ash } \\
\text { (Fraxinus excel- } \\
\text { sior) }\end{array}$ & $50 \times 100 ; 50 \times 150$ & 324 & Glos and Torno (2008a) & $\begin{array}{l}50 \times 100 ; 50 \times 150 \\
25 \times 85 ; 35 \times 160 ; 30 \times 100 \\
30 \times 125 ; 35 \times 100 \\
\quad 35 \times 125\end{array}$ & $\begin{array}{l}259 \\
481\end{array}$ & Kovryga et al. (2019) \\
\hline $\begin{array}{l}\text { European beech } \\
\text { (Fagus sylvatica) }\end{array}$ & $\begin{array}{l}35 \times 70 ; 60 \times 120 ; 60 \times 120 \\
\quad 60 \times 180\end{array}$ & 224 & Glos and Lederer (2000) & $\begin{array}{l}30 \times 120 ; 30 \times 160 \\
30 \times 165\end{array}$ & 217 & Glos and Lederer (2000) \\
\hline Maple (Acer spp.) & $\begin{array}{l}50 \times 100 ; 50 \times 150 \\
50 \times 175\end{array}$ & 459 & Glos and Torno (2008b) & $\begin{array}{l}25 \times 125 ; 30 \times 100 \\
30 \times 125 \\
35 \times 100 ; 35 \times 125 \\
25 \times 100\end{array}$ & 381 & Kovryga et al. (2019) \\
\hline Oak (Quercus spp.) & $40 \times 80 ; 60 \times 120 ; 60 \times 180$ & 336 & Glos and Lederer (2000) & & & \\
\hline Total & & 1343 & & & 1338 & \\
\hline
\end{tabular}


Table 2 Descriptive statistics of grading characteristics and mechanical properties from tension and bending test for European ash (Fraxinus excelsior), European beech (Fagus sylvatica), oak (Quercus spp.) and maple (Acer spp.) species

\begin{tabular}{|c|c|c|c|c|c|c|c|c|}
\hline \multirow[t]{2}{*}{ Species } & & \multicolumn{4}{|c|}{ Bending } & \multicolumn{3}{|l|}{ Tension } \\
\hline & & Ash & Beech & Maple & Oak & Ash & Beech & Maple \\
\hline \multicolumn{2}{|l|}{$N$} & 324 & 224 & 459 & 336 & 740 & 217 & 381 \\
\hline \multirow[t]{2}{*}{$t K A R[-]$} & $\mu$ & 0.055 & 0.102 & 0.075 & 0.175 & 0.067 & 0.146 & 0.119 \\
\hline & $s$ & 0.074 & 0.106 & 0.082 & 0.141 & 0.092 & 0.107 & 0.135 \\
\hline \multirow[t]{2}{*}{$E_{d y n, u s, 12}[\mathrm{GPa}]$} & $\mu$ & 16.1 & 18.1 & 15.1 & 13.4 & 16.5 & 17.7 & 16.7 \\
\hline & $s$ & 1.9 & 1.9 & 2.0 & 2.3 & 2.5 & 2.2 & 1.9 \\
\hline \multirow[t]{2}{*}{$E_{d y n, f r e q, 12}[\mathrm{GPa}]$} & $\mu$ & 14.0 & 14.3 & 12.8 & 11.0 & 14.7 & 14.7 & 14.4 \\
\hline & $s$ & 1.8 & 2.8 & 1.7 & 2.1 & 2.4 & 2.0 & 1.7 \\
\hline \multirow[t]{2}{*}{$\mathrm{MC}[\%]$} & $\mu$ & 10.6 & 11.6 & 8.4 & 31.9 & 10.6 & 10.2 & 11.2 \\
\hline & $s$ & 0.9 & 0.6 & 0.9 & 9.5 & 1.0 & 0.4 & 0.6 \\
\hline \multirow[t]{2}{*}{$\rho_{12}\left[\mathrm{~kg} / \mathrm{m}^{3}\right]$} & $\mu$ & 678 & 742 & 635 & 714 & 685 & 723 & 664 \\
\hline & $s$ & 49 & 38 & 41 & 55 & 57 & 41 & 45 \\
\hline \multirow[t]{2}{*}{$E_{0,12}[\mathrm{GPa}]$} & $\mu$ & 12.7 & 14.6 & 12.0 & 10.9 & 14.1 & 13.8 & 13.8 \\
\hline & $s$ & 1.8 & 2.4 & 1.9 & 2.8 & 2.7 & 2.5 & 2.2 \\
\hline \multirow[t]{2}{*}{$f[\mathrm{MPa}]$} & $\mu$ & 69.8 & 65.3 & 56.3 & $56.1 *$ & 59.0 & 48.2 & 53.4 \\
\hline & $s$ & 16.1 & 20.7 & 18.7 & $17.2^{*}$ & 28.2 & 22.1 & 26.2 \\
\hline
\end{tabular}

$* \mathrm{f}_{\mathrm{m}}$ values for oak are adjusted to $12 \% \mathrm{MC} ; \mathrm{f}_{\mathrm{m}}(\mu \pm \mathrm{s})$ in wet conditions $38.7 \pm 11.7[\mathrm{MPa}]$ are comparable to the values reported by Frühwald and Schickhofer (2005). For beech, the values are lower compared to the ungraded tensile strength values reported by Ehrhart et al. $2016\left(f_{t, \text { mean }}=66.7 \mathrm{MPa}\right)$ and by Frühwald and Schickhofer $(2005)\left(f_{t, \text { mean }}=62.2 \mathrm{MPa}\right)$. On the other hand, the values considerably exceed the values reported by Westermayr et al. (2018) $\left(f_{t, \text { mean }}=35.9 \mathrm{MPa}\right)$ for lowquality beech lamella. Oak was tested at higher moisture content (MC), which was on average $31.9 \%$. Therefore, the values are adjusted to the reference $\mathrm{MC}$ of $12 \%$ as described in Sect. 3.3. For species other than oak, only static MOE is adjusted to the reference MC; the strength is not adjusted as specimens are tested close to reference conditions $\left(20^{\circ} \mathrm{C}\right.$ and $65 \%$ relative humidity). The bending strength values of oak adjusted to $12 \% \mathrm{MC}$ are lower compared to beech or ash and are comparable to the ones reported by Faydi et al. (2017) with a mean value of $56 \mathrm{MPa}$ and $\mathrm{CoV}$ of $39 \%$.

\section{Methods}

\subsection{Non-destructive measurements}

For all the specimens, the grading characteristics were determined. The $E_{d y n}$ was measured in two ways-using the ultrasound wave propagation and the longitudinal vibration (LV) method. The longitudinal US measurement was taken using Sylvatest device (Sandoz 1996) with a frequency of $20 \mathrm{kHz}$. During the non-destructive measurement, the runtime of the wave is measured longitudinal to the grain direction between the transmitting and receiving transducer.
The $E_{d y n}$ is calculated as a product of density $\rho$ and ultrasound wave $v$ using Eq. 1:

$E_{d y n, u s}=v^{2} \cdot \rho$

For the LV method, a hammer is used to generate stress waves. The signal is recorded by means of a microphone or an accelerometer. Both measurements are taken at the laboratory of the TU Munich for repeatability check, as they provide similar results. In industrial facilities, a laser vibrometer can be used to record vibrations contact-free. By applying the FFT-transformation, the eigenfrequency is calculated. The $E_{d y n, f r e q}$ is calculated by combining the first eigenfrequency $(f)$ with length $(l)$ of the specimen and density $(\rho)$ measurement using the following equation:

$E_{\text {dyn.freq }}=4 \cdot l^{2} \cdot f^{2} \cdot \rho$

The density is measured by weighing the specimen.

For temperate hardwoods, density usually shows no correlation to the tensile and bending strength (Ehrhart et al. 2016; Westermayr et al. 2018; Frühwald and Schickhofer 2005). Therefore, $E_{d y n}$ was calculated using a constant density value to study the effect of eigenfrequency and ultrasound velocity on the strength properties. For each wood species, the average density from Table 2 was taken into account. The difference between the $E_{d y n}$ calculated with individual density readings and $E_{d y n}$ with an average density of the wood species is discussed in the paper.

To separate low- and high-quality specimens, the knottiness parameter $t K A R$ (total knottiness area ratio) is used. $t K A R$ is a parameter frequently used in scientific publications and in national visual grading standards, such as BS 
4978. It is calculated as the area of knots appearing in a $150 \mathrm{~mm}$ long part of the specimen, projected on the crosssectional area. The overlapping areas are counted once.

\subsection{Destructive tests}

The hardwood specimens were tested in tension and in bending according to the test specification of EN 408 (2010) valid at the time of testing. The bending strength and local MOE were measured in a four-point bending test. The test span between the two loading points was six times the depth of the cross-section. For local MOE, the deformation was measured over the length of five times the depth. The tensile strength was determined with the free test length of nine times the height and the gauge length for the tensile MOE measurement was five times the height.

\subsection{Moisture content adjustment}

The mechanical properties were adjusted to the reference conditions $20{ }^{\circ} \mathrm{C}$ and $65 \%$ relative humidity. For all species, the equation derived by Nocetti et al. (2015) on chestnut was used to adjust dynamic and static MOE. The procedure in EN 384 does not specify any adjustment factors for MC above $18 \%$. For MOE below fiber saturation point (FSP), Eq. 3 was used.

$E_{12}=\frac{E_{u}}{1-0.005(u-12)}$

where $E_{u}$ is the MOE measured at a certain moisture content level and $\mathrm{u}$ is the moisture content.

For changes in MC above FSP, Eq. 4 was used:

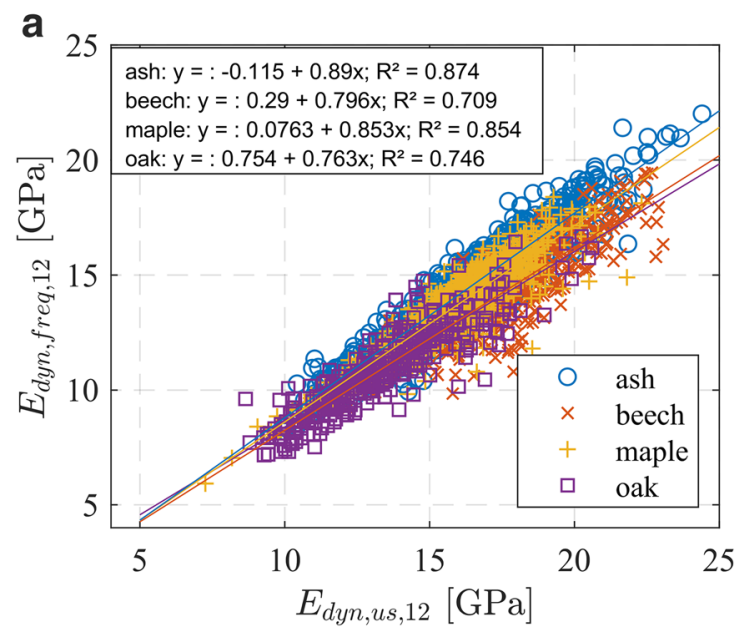

$E_{12}=\frac{E_{u}}{0.9}$

The equation assumes a constant MOE value above FSP also shown by Unterwieser and Schickhofer (2011).

The bending strength $\left(f_{m}\right)$ values are adjusted to the reference conditions by assuming a $1.4 \%$ increase in strength per $1 \% \mathrm{MC}$ decrease up to fiber saturation point (Hernández et al. 2014). The selected factor is supported by the findings of Glos and Lederer (2000) for the tested sample who found the difference in bending strength between green and dry specimens of about $21 \%$. The selected factor is designated on the safe side, as in some publications higher change rate is reported. Wang and Wang (1999) report a change rate of $3.9 \%$ in bending strength per $1 \% \mathrm{MC}$ change for red oak.

\subsection{Statistical analysis}

For the statistical analysis, the linear regression and correlation analyses were used. To analyse the performance of LV and US for the strength and stiffness prediction, the samples were grouped by the destructive testing mode (bending, tension) after the grading and by the wood species. For each group, the correlation analysis was applied by calculating the Pearson correlation coefficient.

\section{Results and discussion}

\subsection{Longitudinal vibration method vs. ultrasound measurement}

Figure 1 shows the relationship between $E_{d y n}$ from the US and LV measurements. Generally, high consistency between

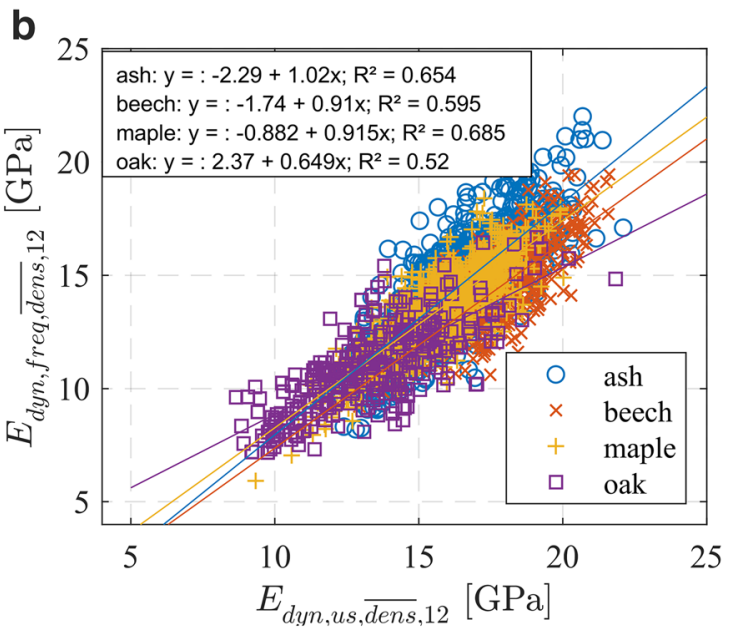

Fig. 1 Relationship between $E_{d y n}$ from US measurement and $E_{d y n}$ measured using LV method with $E_{d y n}$ calculated a with individual density reading and $\mathbf{b}$ calculated with constant density value, grouped by the hardwood species 
both measurements across the wood species can be observed. The coefficient of determination between ultrasound $E_{d y n}$ and eigenfrequency $E_{d y n}$ ranges between 0.7 for beech and 0.87 for ash. If the $E_{d y n}$ is calculated using average density (Fig. 1b), the overall $R^{2}$ value drops and the scatter shows significantly higher variation. Therefore, individual density values provide a homogenizing effect on the relationship between the $E_{d y n}$ from the US and LV measurements. Major differences in the prediction of grade determining properties, like strength and stiffness, are, therefore, expected for the $E_{d y n}$ without considering the density.

\subsection{Stiffness prediction}

The coefficient of determination for the tensile and bending MOE is shown in Table 3. $E_{d y n}$ from LV measurement shows higher $R^{2}$ values compared to the US measurement. Whereas for oak the difference is less pronounced, the difference for beech and maple increases up to max. 0.3. The prediction strength of static MOE drops for both $E_{d y n}\left(E_{d y n, f r e q, \overline{d e n s}, 12}\right.$ and $\left.E_{d y n, u s, \overline{d e n s}, 12}\right)$ calculated with average density.

The coefficient of determination between US $E_{d y n}$ and LV $E_{d y n}$ is compared for a combined hardwood species data set in Fig. 2 dependent on the testing mode. The LV $E_{d y n}$ scatters less compared to the US measurement. For both measurements, the regression equation seems to predict tensile and bending MOE similarly well. The scatter has a similar shape. However, the variation around the regression line is higher for the correlation to the bending stiffness. For the specimens tested in tension, $E_{\mathrm{t}}$ shows larger scatter with values up to $22 \mathrm{GPa}$.

The possibility of combining the wood species for the species-independent strength grading is visualized in Fig. 3. For both testing modes (bending and tension), the population of temperate European hardwoods shows homogenous scatter. The values scatter approximately within the same range. For ash in tension, the stiffness is slightly higher compared to beech and maple. Furthermore, specimens show,
Table 3 Coefficient of determination $\left(R^{2}\right)$ for the prediction of density, modulus of elasticity and strength from bending and tension tests for European ash (Fraxinus excelsior), European beech (Fagus sylvatica), oak (Quercus spp.) and maple (Acer spp.) species

\begin{tabular}{|c|c|c|c|c|c|c|}
\hline & \multicolumn{3}{|c|}{ Bending } & \multicolumn{3}{|c|}{ Tension } \\
\hline & $\rho_{12}$ & $E_{0,12}$ & $f_{m}$ & $\rho_{12}$ & $E_{0,12}$ & $f_{t}$ \\
\hline \multicolumn{7}{|l|}{ European ash } \\
\hline$\rho_{12}$ & 1 & 0.234 & 0.036 & 1 & 0.298 & 0.034 \\
\hline$E_{d y n, u s, 12}$ & 0.415 & 0.651 & 0.119 & 0.424 & 0.658 & 0.148 \\
\hline$E_{d y n, f r e q, 12}$ & 0.312 & 0.778 & 0.282 & 0.386 & 0.749 & 0.270 \\
\hline$E_{d y n, u s, \overline{d e n s}, 12}$ & 0.008 & 0.467 & 0.092 & 0.054 & 0.509 & 0.149 \\
\hline$E_{\text {dyn,freq, } \overline{\text { dens }}, 12}$ & 0.002 & 0.568 & 0.269 & 0.047 & 0.591 & 0.296 \\
\hline $\mathrm{MC}$ & 0.116 & 0.009 & 0.009 & 0.012 & 0.059 & 0.009 \\
\hline \multicolumn{7}{|c|}{ European beech } \\
\hline$\rho_{12}$ & 1 & 0.066 & 0.034 & 1 & 0.172 & 0.010 \\
\hline$E_{d y n, u s, 12}$ & 0.369 & 0.386 & 0.202 & 0.475 & 0.625 & 0.188 \\
\hline$E_{d y n, f r e q, 12}$ & 0.287 & 0.699 & 0.407 & 0.351 & 0.847 & 0.386 \\
\hline$E_{d y n, u s, \overline{d e n s}, 12}$ & 0.038 & 0.350 & 0.187 & 0.103 & 0.575 & 0.246 \\
\hline$E_{\text {dyn,freq, } \overline{\text { dens }}, 12}$ & 0.039 & 0.661 & 0.393 & 0.054 & 0.772 & 0.471 \\
\hline $\mathrm{MC}$ & 0.191 & 0.053 & 0.070 & 0.020 & 0.025 & 0.002 \\
\hline \multicolumn{7}{|l|}{ Maple } \\
\hline$\rho_{12}$ & 1 & 0.078 & 0.017 & 1 & 0.031 & 0.029 \\
\hline$E_{d y n, u s, 12}$ & 0.238 & 0.666 & 0.163 & 0.364 & 0.319 & 0.007 \\
\hline$E_{d y n, f r e q, 12}$ & 0.201 & 0.792 & 0.312 & 0.207 & 0.598 & 0.142 \\
\hline$E_{d y n, u s, \overline{d e n s}, 12}$ & 0.005 & 0.573 & 0.144 & 0.009 & 0.348 & 0.054 \\
\hline$E_{d y n, f r e q, \overline{d e n} s, 12}$ & 0.002 & 0.674 & 0.285 & 0.002 & 0.558 & 0.263 \\
\hline $\mathrm{MC}$ & 0.000 & 0.077 & 0.085 & 0.067 & 0.002 & 0.000 \\
\hline \multicolumn{7}{|l|}{ Oak } \\
\hline$\rho_{12}$ & 1 & 0.007 & 0.009 & & & \\
\hline$E_{d y n, u s, 12}$ & 0.209 & 0.554 & 0.312 & & & \\
\hline$E_{d y n, f r e q, 12}$ & 0.192 & 0.572 & 0.398 & & & \\
\hline$E_{d y n, u s, \overline{d e n s}, 12}$ & 0.022 & 0.482 & 0.252 & & & \\
\hline$E_{d y n, f r e q, \overline{d e n s}, 12}$ & 0.025 & 0.521 & 0.345 & & & \\
\hline $\mathrm{MC}$ & 0.083 & 0.000 & 0.028 & & & \\
\hline
\end{tabular}





Fig. 2 Scatterplot between a $E_{d y n}$ measured using US device and static MOE and $\mathbf{b} E_{d y n}$ measured using LV method and static MOE for all investigated hardwood species, split by the testing mode (bending, tension)
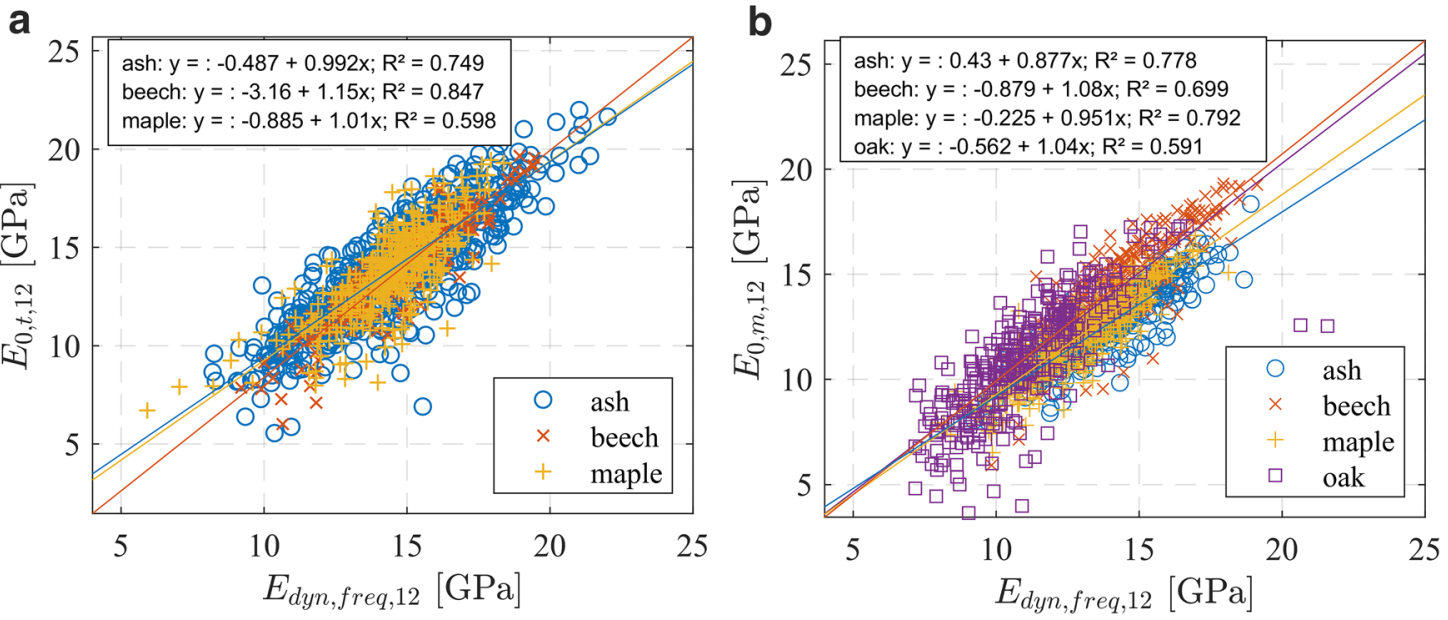

Fig. 3 Relationship between a $E_{d y n}$ measured using LV method and tension MOE and $\mathbf{b} E_{d y n}$ measured using LV method and bending MOE, grouped by the hardwood species

in particular for tension test specimens, almost parallel slope of the regression line. The observation supports the approach by Ravenshorst (2015) regarding the applicability of the species-independent strength grading to the example of tension data.

\subsection{Strength prediction}

The bending and tensile strengths are predicted with US $\left(E_{d y n, u s, 12}\right)$ less accurately compared to the $\operatorname{LV}\left(E_{d y n, f r e q, 12}\right)$. The accuracy ranges between 0.007 and 0.312 for the US and 0.142 and 0.407 for the LV. The $R^{2}$ values between $E_{d y n, f r e q, 12}$ and strength $\left(f_{t}\right.$ and $\left.f_{m}\right)$ are approximately two times higher compared to the values between $E_{d y n, u s, 12}$ and strength. These findings support the results of Frühwald and
Hasenstab (2010), who came to the conclusion that $E_{d y n}$ from $\mathrm{LV}$ is a better predictor for the tensile strength.

The scatter between $E_{d y n}$ calculated with average density and tensile strength is visualized for the frequency measurement in Fig. 4. The scatter for the US shows a similar pattern but higher variation (not shown here). The values for all the species fall within the same range and support the idea of species-independent scatter. In particular, for the tensile strength, the scatter is very similar. The slopes of the regression lines are almost equal, allowing for a speciesindependent strength grading.

The use of ultrasound and eigenfrequency $E_{d y n}$ depends on the density value used for the calculation of the $E_{d y n}$. If the average density value of the wood species is used for the calculation of $E_{d y n}$ and not the individual density value, 



Fig. 4 Relationship between a $E_{d y n}$ measured using LV and tensile strength and $\mathbf{b} E_{d y n}$ measured using LV and bending strength, grouped by hardwood species

the strength coefficient of determination increases for some samples. For specimens tested in tension, a clear increase in coefficient of determination is observable, while for the specimens tested in bending, the exclusion of density value leads to a slight drop in $R^{2}$ values ( 0.015 on average). The same results have been shown by Nocetti et al. (2016) on chestnut timber tested in bending. The coefficient of determination for $\mathrm{LV}$ bending strength prediction decreased from 0.24 to 0.15 . This behaviour is most likely attributed not only to the testing mode but rather to specimen dimensions and sawing pattern used.

Figure 5 exemplarily visualizes the difference in coefficient of determination of the tensile strength using $E_{d y n}$ calculated with average density and individual density for European ash. For the relationship between $E_{d y n}$ calculated with average density and tensile strength, a scatter with less variation and steeper regression line can be observed. As a consequence of lower variation around the regression line, higher $R^{2}$ value can be achieved. By calculating with an average density, the variation in $E_{d y n}$ is reduced. The density is a part of $E_{d y n}$ calculation that shows either low correlation or no correlation to the timber strength. In the case of maple, the correlation is even negative $(r=-0.120)$.

The observable differences in strength prediction are most likely attributed to the cross-section size and the sawing pattern used. This can be observed on the ash tested in tension which comprises two sub-samples. The first subsample includes timber of thicker cross-section $(50 \times 100$ and $50 \times 150$ ) and cut with "cutting all around" (without pith) pattern and the second sub-sample includes smaller
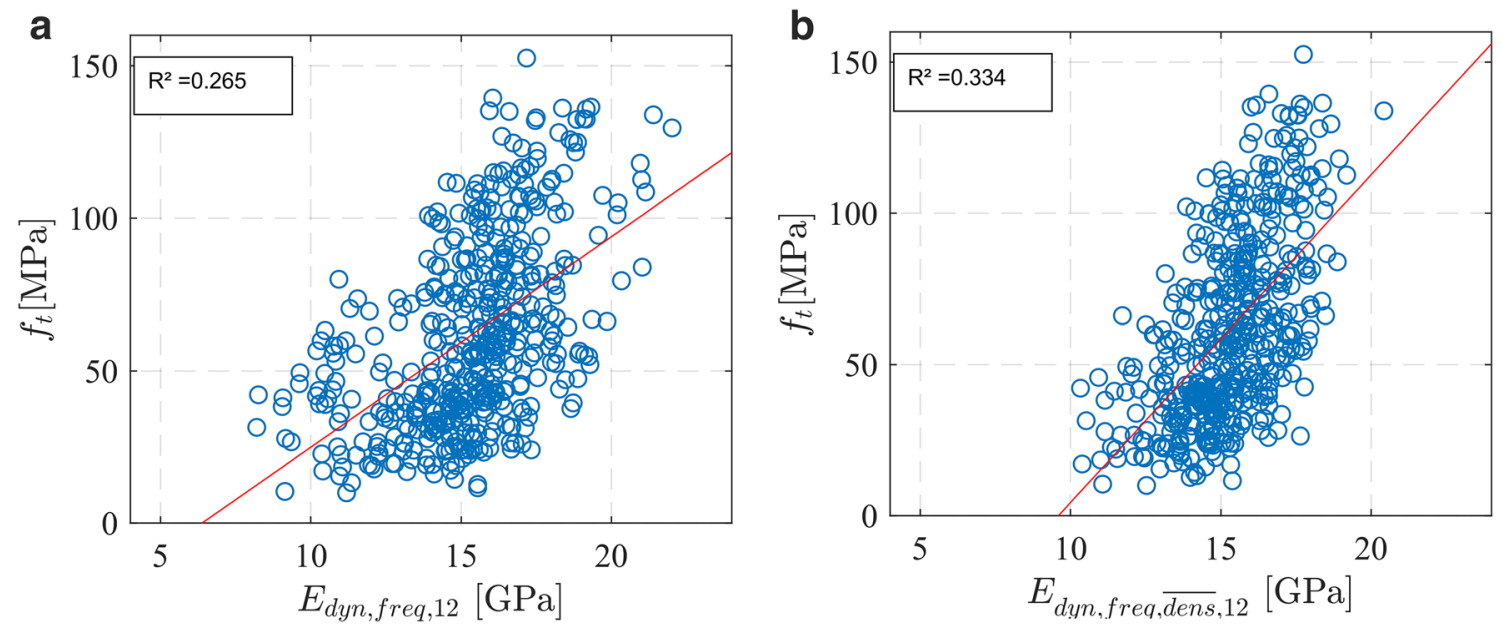

Fig. 5 Relationship between tensile strength and $E_{d y n}$ measured by using LV method and calculated with the individual (a) and average density (b) for European ash (Fraxinus excelsior) sub-sample tested by Kovryga et al. (2019) $(N=481)$ 

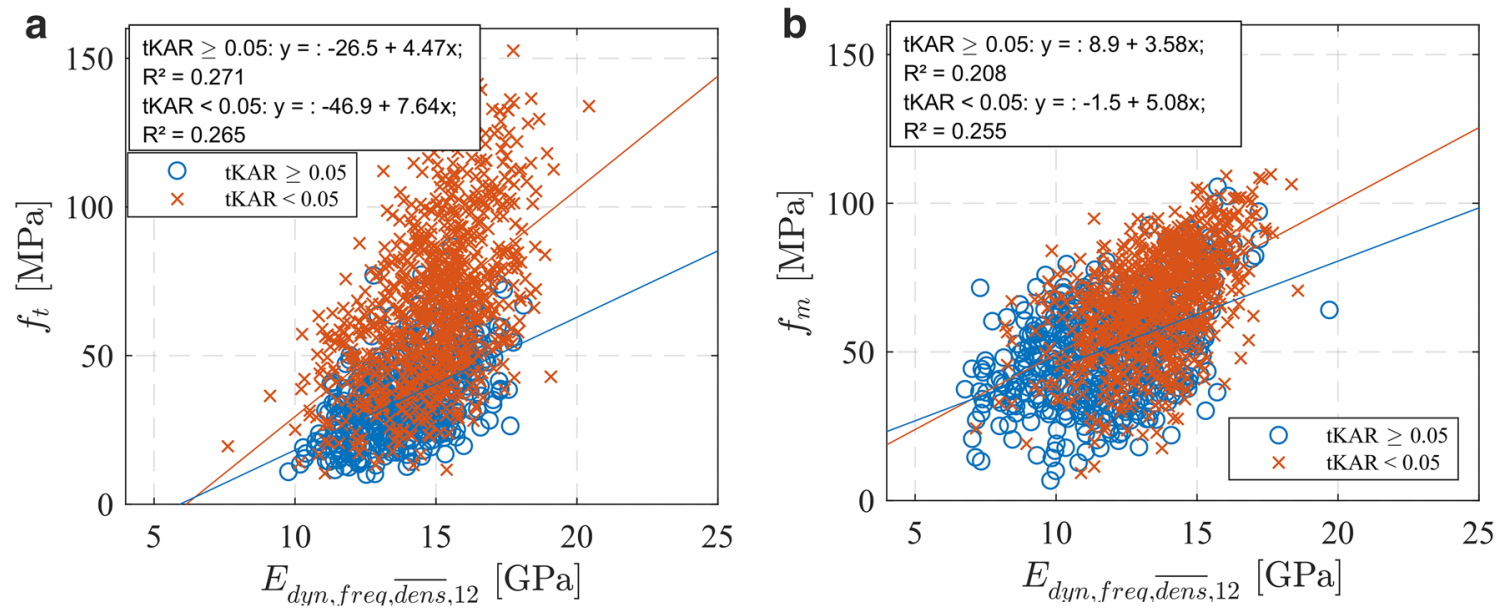

Fig. 6 Relationship between $\mathbf{a} \mathrm{E}_{\mathrm{dyn}}$ measured using LV and tensile strength and $\mathbf{b} E_{d y n}$ measured using LV and bending strength, for a combination of hardwood species, grouped in knot-free specimens $(t K A R<0.05)$ and specimens with knots $(t K A R>0.05)$

cross-sections $(25 \times 85$ to $35 \times 165$ tested by Kovryga et al. 2019, Table 1) cut with a sawing pattern that included the pith. For the larger samples, no significant difference in coefficient of determination using $E_{d y n, f r e q, 12}$ and $E_{d y n, f r e q, \overline{d e n}, 12}$ was observable. In contrast, for smaller ash dimensions, the coefficient of determination increased from 0.265 to 0.334 by using average density instead of individual reading. The juvenile wood present in the sawing pattern with pith is known for temperate hardwoods to have slightly higher density compared to the mature wood (e.g., Woodcock and Shier 2002; Gryc et al. 2008). Therefore, a higher share of pith specimens could negatively affect the applicability of the density to $E_{d y n}$ calculation for strength prediction. For those specimens, higher density of juvenile wood increases the numeric value of the $E_{d y n}$, which would also indicate/evidence higher strength, which is obvioulsy not the case for juvenile wood. To make general conclusions and study the causes, a special testing program is required.

Additionally, the effect of the wood quality on the relationship between $E_{d y n}$ and strength can be observed in Fig. 6 . The wood quality was defined as knot-free specimens and specimens with $t K A R>0.05$. For the tensile and bending strength predictions, the greater slope of the regression line is visible on the knotfree specimens. In the case of tensile strength, the difference is even more pronounced. Although the $R^{2}$ value does not differ significantly between knot-free $(t K A R<0.05)$ and specimens with knots, the variation of measured values around the regression line in the case of knot-free specimens is greater. For bending strength, the coefficient of determination is slightly higher.

\section{Conclusion}

In this paper, the differences between the coefficient of determination of the dynamic MOE measured by using US and LV methods were studied. The $E_{d y n}$ measured by using LV results in higher coefficient of determination for the strength and stiffness. Nevertheless, the accuracy of the ultrasound $E_{d y n}$ is high as well, especially for the MOE prediction. The results also support the findings of Ravenhorst (2015) for the species-independent strength grading for both bending strength and tensile strength. The same regression equation can be used to predict both tensile MOE and bending MOE with $E_{d y n}$. Furthermore, the effect of wood quality or knottiness of the wood on the grading accuracy was observed. Whereas for tension specimens the coefficient of determination did not differ much, the slope of the regression line and the scatter differ significantly. For tension test specimens, the use of average density in $E_{d y n}$ calculation increases the coefficient of determination for strength prediction. This could be caused by smaller cross-sections of the tested specimens, as well as by the different sawing patterns. Further research is required to better understand the wave propagation in such specimens.

Acknowledgements Open Access funding provided by Projekt DEAL.

Open Access This article is licensed under a Creative Commons Attribution 4.0 International License, which permits use, sharing, adaptation, distribution and reproduction in any medium or format, as long as you give appropriate credit to the original author(s) and the source, provide a link to the Creative Commons licence, and indicate if changes were made. The images or other third party material in this article are included in the article's Creative Commons licence, unless indicated 
otherwise in a credit line to the material. If material is not included in the article's Creative Commons licence and your intended use is not permitted by statutory regulation or exceeds the permitted use, you will need to obtain permission directly from the copyright holder. To view a copy of this licence, visit http://creativecommons.org/licenses/by/4.0/.

\section{References}

Bacher M (2008) Comparison of different machine strength grading principles. In: Proceedings of COST E53 Conference, October 29-30, Delft, The Netherlands, pp 183-193

Daval V, Pot G, Belkacemi M, Meriaudeau F, Collet R (2015) Automatic measurement of wood fiber orientation and knot detection using an optical system based on heating conduction. Opt Express 23(26):33529-33539. https://doi.org/10.1364/ OE.23.033529

Ehrhart T, Fink G, Steiger R, Frangi A (2016) Experimental investigation of tensile strength and stiffness indicators regarding European beech timber. In: Proceedings of the World Conference on Timber Engineering 2016 (WCTE 2016), August 22-25, Vienna, Austria

Ehrhart T, Steiger R, Frangi A (2018) A non-contact method for the determination of fibre direction of European beech wood (Fagus sylvatica L.). Eur J Wood Prod 76(3):925-935. https://doi. org/10.1007/s00107-017-1279-3

EN 408 (2010) Timber structures-structural timber and glued laminated timber-determination of some physical and mechanical properties. CEN European Committee for Standardization, Brussels

Faydi Y, Brancheriau L, Pot G, Collet R (2017) Prediction of oak wood mechanical properties based on the statistical exploitation of vibrational response. BioResources 12(3):5913-5927. https:// doi.org/10.15376/biores.12.3

Frühwald K, Schickhofer G (2005) Strength grading of hardwoods. Proceedings of the 14th International Symposium on Nondestructive Testing of Wood, May 2-4, Hannover, Germany, pp 198-210

Frühwald K, Hasenstab A (2010) Zerstörungsfreie Prüfung von Laubholz in Holzbauprodukten und im eingebauten Zustand (Nondestructive testing of hardwood in structural timber products and when built-in) (In German). In: Fachtagung Bauwerksdiagnose, February 18-19, Berlin, Germany, pp 17-18

Giudiceandrea F (2005) Stress grading lumber by a combination of vibration stress waves and Xray scanning. In: 11th International Conference on Scanning Technology and Process Optimization in the Wood Industry (ScanTech 2005), Wood Machining Institute, Walnut Creek, California, pp 99-108

Glos P, Lederer B (2000) Sortierung von Buchen- und Eichenschnittholz nach der Tragfähigkeit und Bestimmung der zugehörigen Festigkeits- und Steifigkeitskennwerte (Strength grading of beech and oak sawn lumber and determination of characteristic strength and stiffness values). Report No. 98508, Holzforschung München, Munich

Glos P, Torno S (2008a) Allocation of ash and poplar of German origin to EN 1912. Report No. TG1/0508/16, TU München, Munich

Glos P, Torno S (2008b) Allocation of maple of German origin to EN 1912. Report No. TG1/1108/26, TU München, Munich

Görlacher R (1990) Klassifizierung von Brettschichtholzlamellen durch Messung von Longitudinalschwingungen (Grading of glulam lamellas by longitudinal vibration measurement), Dissertation. Universität Karlsruhe, Karlsruhe

Green DW, McDonald KA (1993) Mechanical properties of red maple structural lumber. Wood Fibre Sci 25(4):365-374

Gryc V, Vavrčík H, Rybníček M, Přemyslovská E (2008) The relation between the microscopic structure and the wood density of European beech (Fagus sylvatica L.). J Forest Sci 54(4):170-175

Hernández RE, Passarini L, Koubaa A (2014) Effects of temperature and moisture content on selected wood mechanical properties involved in the chipping process. Wood Sci Technol 48(6):12811301. https://doi.org/10.1007/s00226-014-0673-9

Kollmann FFP, Côté WA (1968) Principles of wood science and technology I. Solid wood. Springer-Verlag, Berlin

Kovryga A, Schlotzhauer P, Stapel P, Militz H, van de Kuilen J-WG (2019) Visual and machine strength grading of European ash and maple for glulam application. Holzforschung. https://doi. org/10.1515/hf-2018-0142

Kovryga A, Khaloian Sarnaghi A, van de Kuilen JWG (2020) Strength grading of hardwoods using transversal ultrasound. Eur J Wood Prod. https://doi.org/10.1007/s00107-020-01573-2

Nocetti M, Brunetti M, Bacher M (2015) Effect of moisture content on the flexural properties and dynamic modulus of elasticity of dimension chestnut timber. Eur J Wood Prod 73(1):51-60. https ://doi.org/10.1007/s00107-014-0861-1

Nocetti M, Brunetti M, Bacher M (2016) Efficiency of the machine grading of chestnut structural timber: prediction of strength classes by dry and wet measurements. Mater Struct 49(11):4439 4450. https://doi.org/10.1617/s11527-016-0799-3

Olsson A, Pot G, Viguier J, Faydi Y, Oscarsson J (2018) Performance of strength grading methods based on fibre orientation and axial resonance frequency applied to Norway spruce (Picea abies L.), Douglas fir (Pseudotsuga menziesii (Mirb.) Franco) and European oak (Quercus petraea (Matt.) Liebl./Quercus robur L.). Ann Forest Sci 75(4):33529. https://doi.org/10.1007/s13595-018-0781-z

Ravenshorst GJP (2015) Species independent strength grading of structural timber. Technische Universiteit Delft, Delft

Sandoz JL (1996) Ultrasoinc solid wood evaluation in industiral spplications. In: Proceedings of the 10th International Symposium on Nondestructive Testing of Wood, 26-28 September 1996, Lausanne, Switzerland

Unterwieser H, Schickhofer G (2011) Influence of moisture content of wood on sound velocity and dynamic MOE of natural frequencyand ultrasonic runtime measurement. Eur J Wood Prod 69(2):171181. https://doi.org/10.1007/s00107-010-0417-y

Wang S-Y, Wang H-L (1999) Effects of moisture content and specific gravity on static bending properties and hardness of six wood species. J Wood Sci 45(2):127-133. https://doi.org/10.1007/BF011 92329

Westermayr M, Stapel P, van de Kuilen JWG (2018) Tensile strength and stiffness of low quality beech (Fagus sylvatica) sawn timber. In: Proceedings of the World Conference on Timber Engineering 2018 (WCTE 2018), August 20-23, Seul, Republic of Korea

Woodcock DW, Shier AD (2002) Wood specific gravity and its radial variations: the many ways to make a tree. Trees 16(6):437-443. https://doi.org/10.1007/s00468-002-0173-7

Publisher's Note Springer Nature remains neutral with regard to jurisdictional claims in published maps and institutional affiliations. 